2020, Vol: 21, pp. 28-39, DOI: 10.18038/estubtda.818451

\title{
THE EFFECT OF COLEMANITE ADDITION ON THE MICROSTRUCTURAL AND MECHANICAL CHARACTERISTICS OF IPP
}

\author{
Uğur SOYKAN 1,*i] , Fidan VELIYEVA 2 (99) \\ ${ }^{1}$ Yenicaga Yasar Celik Vocational High School, Bolu Abant Izzet Baysal University, Bolu-Turkey, 14300 \\ ${ }^{2}$ Department of Chemistry, Bolu Abant Izzet Baysal University, Bolu-Turkey, 14000
}

\begin{abstract}
The objective of this study was to investigate the effect of the addition of the colemanite having $45 \mu \mathrm{m}$ size on the significant characteristic features of the isotactic polypropylene (IPP). The microstructural properties (diffraction pattern, $a, b$ and $c$ unit cell parameters and grain size) and mechanical behaviors (tensile strength, Young's Modulus, impact strength and percent elongation of the samples relative to the colemanite content $(5,10,15,20$ and $30 \mathrm{wt} . \%)$ were studied in details. The optimum amount of colemanite was determined in order to obtain IPP based composites having improved properties. The obtained samples were characterized by using XRD and conventional mechanical tests. The results showed that the content level of the colemanite considerably affected the fundamental properties of IPP. As for microstuructural properties, it was observed from the XRD patterns that all composite samples mainly showed only $\alpha$ form (monoclinic arrangement) in the crystalline domains without any $\beta$ form (hexagonal arrangements). Moreover, the finding revealed that $a$ and $b$ the unit cell parameters of IPP based composites increased initially, reached the maximum values with the products containing $10 \%$ of colemanite, and then the consistent decrement trend was observed with the further increase in the colemanite content in the products. Conversely, $c$ unit cell parameter almost remained relatively unchanged. Furthermore, the mechanical test measurements depicted that the reinforcements were achieved in the tensile, Modulus and impact strengths of the composite materials, while the percent elongation of the products decreased with the increasing of the colemanite content. $7.4 \%, 24.9 \%$ and $6.7 \%$ increases were recorded in the tensile strength, Modulus and impact strength at the product with $10 \%$ colemanite, respectively. The improvements were probably stemmed from that the presence of micro size colemanite particles gave rise to increment in the orientations and alignments of IPP chain in the matrix.
\end{abstract}

Keywords: Colemanite, Unit cell parameters, Mechanical properties, IPP based composites, Percent elongation

\section{INTRODUCTION}

The polymer composites (PCs) can be defined as the materials composed of the polymer (matrix) and the additive (filler) bonded together via the covalent bonds or the weak intermolecular forces [1]. Many fundamental characteristics features can be imparted into the polymeric materials by forming the polymer composites. Thus, they have been an indispensible part of many industrial applications such as advanced materials [2], automotive [3], medicine [4], engineering [5], optics [6], electrical products [7] and textile [8] etc. since they enables to the materials lot of advantages such as mechanical reinforcement, resistance to corrosive, advanced in the polymer processing conditions, thermal stability, microstructural improvements etc [9-12]. Especially, many researchers recently have been focused on the polymer composites containing the inorganic filler or natural fiber with their outstanding properties $[13,14]$. Isotactic polypropylene (IPP), which is one of the significant member of the olefin family, have used widely in the world plastic industry with its excellent comprehensive properties such as low manufacturing cost, high heat resistance, low cost and high mechanical strength [15]. However, the usage of IPP is limited due to some undesired features like absence of reactive site, lower hydrophobic property, sticking challenge during processing, dye uptake and more vulnerable to photo-oxidation etc [16]. In order to deal with these drawbacks, many studies regarding IPP based composites were done so as to modify its mechanical [17], morphological [18], conductive [19], thermal [20] and crystallization properties [21].

*Corresponding Author: ugursoykan@ibu.edu.tr

Received: 30.10.2020 Published: 27.11.2020 
Boron minerals is one of today's natural compounds used in many different industrial areas such as filler, energy, textile, cleaning, agriculture, glass, ceramic and superconductor materials etc [22-26]. Therefore, there existed many studies in literature corresponding to the boron mineral which were utilized as a filler in the polymer composites in order to impart the advanced characteristics such as mechanical, flame retardancy, water absorption etc. to the polymers [27-30]. Furthermore, boron minerals make the scientists unable to fabricate halogen free polymer composite by means of their flame retardant characteristic feature [31, 32]. Among the boron minerals, colemanite, $2 \mathrm{CaO} .3 \mathrm{~B}_{2} \mathrm{O}_{3} .5 \mathrm{H}_{2} \mathrm{O}$ is the indispensable natural mineral due to the fact that not only it is cheap $(\$ 0.215 / \mathrm{kg})$ and eco-friendly but also it was used as filler in the thermoplastics thanks to the thermoplastic reinforcement, thermal stability, flame retardant and a radiation transmitter effects [32]. Isitman and Kaynak studied the improvement of the fire retardancy and mechanical properties of lowdensity polyethylene with decreasing the total filler presenting in the matrix with the use of aluminum hydroxide and colemanite minerals. They revealed that the limiting oxygen index was increased by $1 \%-4 \%$ depending on colemanite content due to its better protecting character of fire residues and being more effectual fuel trapping in the condensed phase. However, Higher ductility and lower elastic modulus were recorded in low density polyethylene due to decrement in the total filler loading in the matrix [33]. Besides, Atikler et. al. investigated the synergistic effect of colemanite in order to improve flame retardancy of polypropylene [34]. The hardness and thermal properties of the polypropylene (PP) composites containing varying amount (12.19, 22.6 and 31.76 wt.\%) of colemanite mineral having $19 \mu \mathrm{m}$ particle size were investigated by Sahin [35]. The results showed that thermal expansion of PP decreased with the addition of colemanite to polymer matrix due to the fact that the colemanite particle had a lower expansion coefficient comparing tp the polymer matrix. Moreover, the Shore D hardness of the IPP based composites increased with the colemanite content. In another foregone study, the colemanite and ulexite as the fillers were added individually to bisphenol A epoxy resins in order to observe the mechanical and thermal changes in the epoxy resin composites [27]. The results showed that maximum reinforcements of the epoxy resin were recorded with the 5\% colemanite content, at further contents, the tensile strength started to decrease due to the exfoliation of colemanite. Furthermore, it was revealed that colemanite showed better synergetic effect on the thermal characteristics of virgin epoxy resin when compared to ulexite. Sen et. al. [36] studied the surface, mechanical and thermal properties of the thermoplastic polyurethane (TPU) by using colemanite mineral. They founded that the mechanical properties (especially tensile elongation and elongation at break) of the TPU composites were enhanced with the addition of colemanite. Moreover, the good thermal stability was observed in TPU composites with higher char yield formation as percentage of colemanite increased in the polymer matrix.

It was deduced that colemanite mineral was used as a filler in many thermoplastic matrix with the purpose of improving mechanical, thermal, flame retardant etc. However, only e few studies are focusing on microsturcture and mechanical properties of isotactic polypropylene (IPP) with the additional of colemanite having certain particle size $(45 \mu \mathrm{m})$. In this study we tried to analyze meticulously the variations of the microsturucture and crucial mechanical characteristics features of IPP with $45 \mu \mathrm{m}$ colemanite loaded at five contents by the weight $(5,10,15,20,30 \mathrm{wt} . \%)$ into the polymer matrix. The optimum colemanite content was determined by making serious discussions over the results by comparing the virgin IPP.

\section{EXPERIMENTAL}

\subsection{Materials}

Isotactic polypropylene (IPP) with MH418 code was purchased from the Turkish Petrochemical Industry (PETKIM) and its density was $0.905 \mathrm{~g} / \mathrm{cm}^{3}$. The colemanite (di-calcium hexaborate pentahydrate) having $45 \mu \mathrm{m}$ particle size with the chemical formula of $2 \mathrm{CaO} .3 \mathrm{~B}_{2} \mathrm{O}_{3} .5 \mathrm{H}_{2} \mathrm{O}$ were supplied from the Eti Mining Operations General Directorate in Turkey as in $1 \mathrm{~kg}$ bag. The chemical 
composition of used colemanite were $\mathrm{B}_{2} \mathrm{O}_{3} 40.00 \pm 0.50 \%, \mathrm{CaO} 27.00 \pm 1.00 \%, \mathrm{SiO}_{2} 4.00 \pm 6.50 \%, \mathrm{SO}_{4}$ 0.60\% max., As 35 ppm max., $\mathrm{Fe}_{2} \mathrm{O}_{3}$ 0.08\% max., $\mathrm{Al}_{2} \mathrm{O}_{3}$ 0.40\% max., $\mathrm{MgO} 3.00 \%$ max., $\mathrm{SrO} 1.50 \%$ max., and $\mathrm{Na}_{2} \mathrm{O} 0.50 \%$ max. Moreover, L.O.I. (loss on ignition), moisture and bulk density values of the used colemanite were $25.00 \%$ max., $1.00 \%$ max. and $1.00 \mathrm{ton} / \mathrm{m}^{3}$ max., respectively.

\subsection{Preparation of IPP Based Composites}

IPP in the granule form firstly transformed into the powder form in order to obtain good homogeneity. For this purpose, granule IPP was dissolved in the xylene (50 g of IPP in $500 \mathrm{ml}$ of xylene) at the boiling temperature of xylene and, refluxed for a day for completely solubility. Then, the dissolved IPP was precipitating with the addition of $250 \mathrm{ml}$ of methanol. After the filtration, the powder IPP was dried under the vacuum at $60^{\circ} \mathrm{C}$ for 6 hours. In order to obtain colemanite-IPP composites, the prepared IPP in the powder form and the colemanite with the varying content levels $(5,10,15,20$ and 30 wt.\%) were mixed in the co-rotating twin screw extruder by using DSM Xplore $15 \mathrm{~mL}$ microcompounder machine. During extrusion processes, the hopper, mixing zone and die temperature and also the screw speed of the extruder were $100 \mathrm{rpm}$ and $210^{\circ} \mathrm{C}$. These parameters were kept constant for the production of all colemanite contents. The extruded samples composed of IPP and 5, $10,15,20$ and $30 \mathrm{wt} . \%$ of colemanite were molded at $220^{\circ} \mathrm{C}$ for barrel and $50^{\circ} \mathrm{C}$ for mould by using DACA Micro Injection Molder. The minimum three samples both in the dogbone shape for the tensile tests (thickness of $2.1 \mathrm{~mm}$, width of $7.6 \mathrm{~mm}$ and gauge length of $50 \mathrm{~mm}$ ) and the rectangular solid shapes for the impact tests (thickness of $1 \mathrm{~mm}$, width of $7 \mathrm{~mm}$ ) were prepared with injection pressure of 8.6 bar.

\subsection{Instruments}

In order to investigate the microstructural properties of IPP based composites, XRD analyses of the molded samples were carried out with the help of Rigaku Multiflex powder X-ray diffractometer system with $\mathrm{CuK} \alpha$ target giving radiation $\left(\lambda=1.54^{\circ}\right)$ over the $2 \theta$ range of $10-60^{\circ}$. The XRD measurements were done at the room temperature via the scanning speed of $5 \% \mathrm{~min}$ and step increment of $0.02^{\circ}$. The samples possessing the same weights were utilized in order to compare the intensities recorded from XRD patterns. Furthermore, the lattice constant parameters $(a, b$ and $c)$ and grain sizes of the IPP domain were determined with the accuracy $\pm 0.01 \AA$ by means of XRD patterns[37]. The tensile test of the samples in the dogbone shapes were conducted according to the standard of ASTM D-638 by using LLYOD LR30K Mechanical Tester. During analyses, the load cell and the crosshead speed were $5 \mathrm{kN}$ and $5 \mathrm{~cm} / \mathrm{min}$, respectively. The stress-strain curves of the IPP based composite species were directly recorded by the instrument software. Moreover, the values of the tensile strengths, Young's Modulus and percent elongations of the samples were obtained from the software of the instrument. The Izod impact tests of the unnotched samples were conducted at room temperature according to ASTM standard of D256 with the use of Coesfeld Material Test Pendulum Impact Tester.

\section{RESULTS AND DISCUSSION}

\subsection{Microstructural Properties of IPP Based Composites}

The effect of different content level of colemanite addition on the microstructural characteristics of IPP based composites was investigated in details using XRD measurements carried out with the usage of the same amount of the products at room temperature. X-ray powder diffraction patterns belonging to neat IPP and IPP based composites were depicted in Figure 1. XRD measurements revealed that the only $\alpha$ form (monoclinic arrangement) was observed in the crystal domains of neat IPP and IPP based composites without any detection of $\beta$ form (hexagonal arrangements). The X-ray diffraction peaks 
recorded at $2 \theta=14.1^{\circ}, 16.8^{\circ}, 18.6^{\circ}, 21.1^{\circ}$ and $21.8^{\circ}$ were attributed to $\alpha(110), \alpha(040), \alpha(130)$, $\alpha(131) / \beta(311)$, and $\alpha(041)$ reflections, as seen in Figure $1[38,39]$. The obtained results showed that the relatively intensity of the products depended highly on the additional of the colemanite contents. Especially, when examining the diffraction peaks corresponding to $\alpha(110)$ and $\alpha(040)$, it was seen that the relative intensity of the products increased with the initial addition levels of colemanite, but decreased with the further colemanite addition. It may be attributed that the presence of the higher amount of colemanite in the IPP matrix brought about the lattice distortion of the crystal structure of the IPP domains. Moreover, the broadening of the diffraction peaks and decrement in the sharpness of the peaks might be seen the experimental evidence for this disorder and defects formed in the crystal structure of the IPP matrices [40].

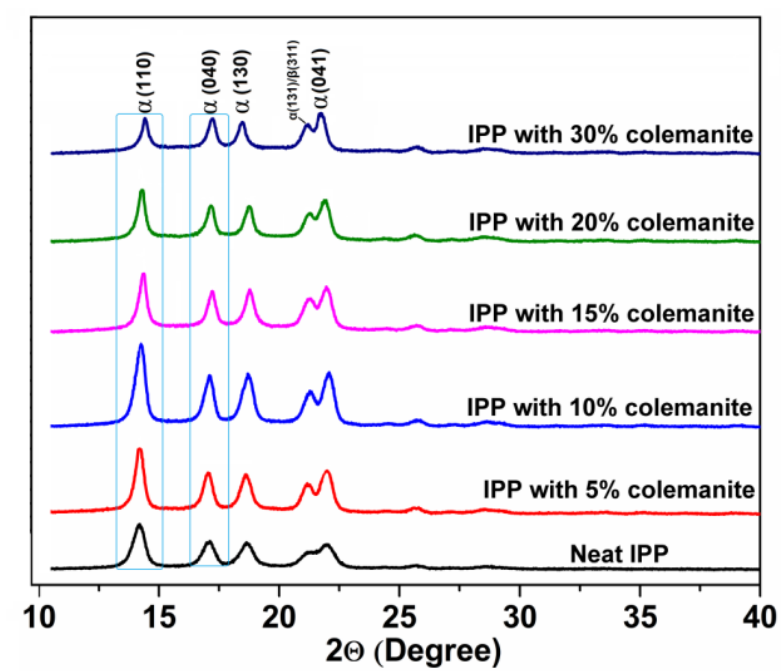

Figure 1. X-ray diffraction patterns belonging to neat IPP and IPP based composites containing 5, 10, 15, 20 ad $30 \%$ colemanite.

The unit cell parameters $(a, b$ and $c)$ regarding to the monoclinic crystalline arrangements of the neat IPP and the composites were calculated by means of XRD patterns. The calculations to determine were carried out depending on the basis the basis of a least square method with the usage of both $\mathrm{d}$ values and $h, k, l$ planes $(040,110,041$ for $a, b, c$ unit cell parameters, respectively. d values of the neat IPP and IPP based composites were obtained directly from the software of the instrument. In addition to that, the crystal sizes (grain sizes) of the neat IPP and IPP based composites were calculated using the following equations ( 1 and 2 ) based on the $\alpha(110)$ main diffraction peak.

$$
\mathrm{B}^{2}=\mathrm{B}_{\mathrm{m}}^{2}-\mathrm{B}_{\mathrm{s}}^{2}
$$

where $B_{s}$ and $B_{m}$ designated the half width of the standard material and the difference between the angles at full width at half maximum (FWHM) of the corresponding peak, respectively.

$$
\mathrm{d}=0.941 \lambda / \mathrm{B} \cos \theta_{\mathrm{B}}
$$

where $d$ showed the thickness of the crystal, $\lambda$ designated the wavelength of the used XRD source, B exhibited sign of FWHM corresponding Bragg peak and also $\theta_{\mathrm{B}}$ implied the Bragg angle.

The findings obtained from the XRD analyses were tabulated in Table 1. It was revealed that the colemanite addition into IPP matrix was considerably influential in the microstructural properties of the IPP. Namely, the initial addition of the colemanite gave rise to the increasing of $\boldsymbol{a}$ and $\boldsymbol{b}$ unit cell parameters, Figure 2.a and b. The maxima, $6.680 \AA$ and $20.821 \AA$ for $\boldsymbol{a}$ and $\boldsymbol{b}(0.83 \%$ and $0.36 \%$ of expansions, respectively) were achieved with the composite sample with $10 \%$ colemanite. This 
expansion was probably caused from that the colemanite having the chemically different character from IPP presumably forced IPP chains, which results in the formation of larger free volumes in the matrix. Thus, IPP chains may form larger monoclinic units during crystallization. However, as the colemanite content reached up to 10\% colemanite content level, these parameters ( $\boldsymbol{a}$ and $\boldsymbol{b})$ depicted the decreasing trend as seen in Figure 2a and b. Even, $\boldsymbol{a}$ and $\boldsymbol{b}$ unit cell parameters reached the minimum values, $6.508 \AA$ and $20.614 \AA$, which was lower than that neat IPP had. These decrements were attributed to the presence of the larger amount of colemanite in the certain area in IPP matrix. In other words, since the unit cell parameter were highly dependence of the filler composition, the further addition of colemanite surrounding IPP molecules in the matrix brought about the inhibiting or preventing effect to form larger IPP monoclinic unit. This resulted in the formation of smaller monoclinic units compared to neat IPP, Figure $2 \mathrm{a}$ and $\mathrm{b}$. On the other hand, XRD results depicted that almost no effect of colemanite addition on the $\boldsymbol{c}$ unit cell parameters of IPP based composites were observed, Figure 2c. This parameter remained almost constant although the colemanite content increased in IPP matrices. This was believed to account for that the chain axis of the IPP molecular segments presenting in the monoclinic arrangements was the parallel with the axis of $\boldsymbol{c}$ unit cell parameter. Thus, any changes were not recorded in $\boldsymbol{c}$ unit cell parameters. Furthermore, as well as unit cell parameters, the founded results as for the crystal sizes of the neat IPP and IPP composites containing varying content of colemanite particles were tabulated in Table 1 and drawn in Figure $2 \mathrm{~d}$. It is to be emphasized that the crystal sizes of the composite sample illustrated the good correlation with the $\boldsymbol{a}$ and $\boldsymbol{b}$ unit cell parameters. That is, the crystal sizes of the composite increased with the initial addition of the colemanite, after maximum, the drastic decrements were observed, Figure $2 \mathrm{~d}$. At low colemanite content, the colemanite particle may assist the ordered nucleation of the IPP crystals, causing the formation of larger crystals. However, the high presence of colemanite particles in the matrix might prevent the development of the IPP crystals, which results in the smaller IPP crystals in the matrices.

Table 1. The dependence of the unit cell parameters a, b and c, and crystal size of IPP samples on the colemanite content in the matrices.

\begin{tabular}{ccccc}
\hline Species & $\boldsymbol{a}(\mathbf{A})$ & $\boldsymbol{b}(\mathbf{A})$ & $\boldsymbol{c}(\mathbf{A})$ & Crystal size $(\mathbf{n m})$ \\
\hline Neat IPP & 6.625 & 20.745 & 6.538 & 16.97 \\
$5 \%$ & 6.633 & 20.786 & 6.539 & 18.33 \\
$10 \%$ & 6.680 & 20.821 & 6.537 & 21.39 \\
$15 \%$ & 6.621 & 20.739 & 6.537 & 16.05 \\
$20 \%$ & 6.573 & 20.652 & 6.536 & 15.85 \\
$30 \%$ & 6.508 & 20.614 & 6.536 & 15.11 \\
\hline
\end{tabular}



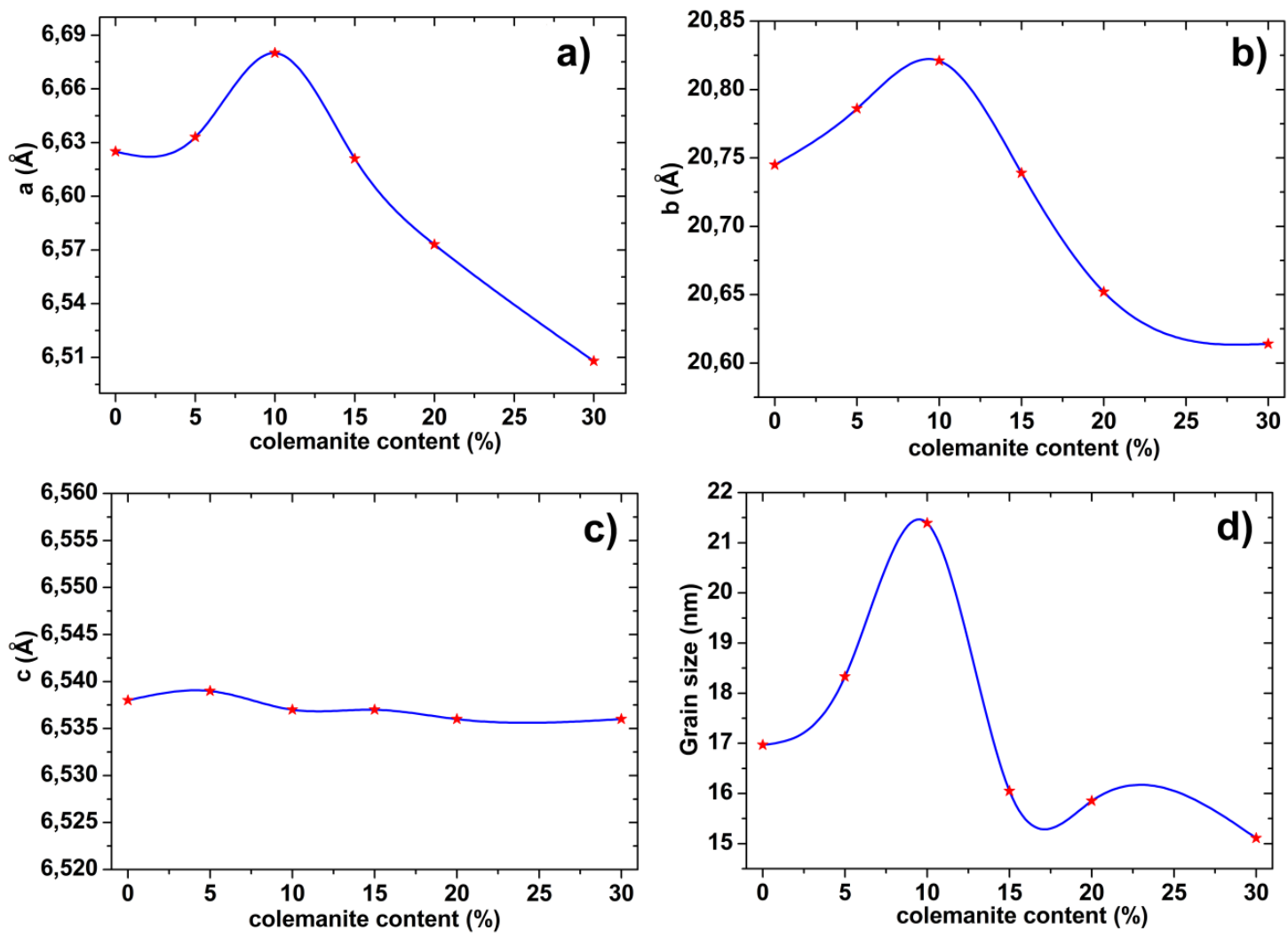

Figure 2. The variation of $\boldsymbol{a}, \boldsymbol{b}, \boldsymbol{c}$ and crystal size with colemanite content

\subsection{Mechanical Characteristics of IPP Based Composites}

In order to unfold the effect of colemanite content on the mechanical characteristics of IPP, the mechanical behavior of the IPP based composites were investigated in details. Prior to the discussion of the results, it was to be stated that the micro injection molding temperature and injection pressure during the preparation of the test samples were determined as $220^{\circ} \mathrm{C}$ and 8.6 bar to cope with the difficulties in the flow and viscosity. Thus, at this condition, both the ideal dispersion and good melt flow were achieved in the products. The representative stress-strain curves of the neat IPP and IPP based composites with 5, 10, 15, 20 and 30\% colemanite were depicted in Figure 3, which determined by using $5 \mathrm{~cm} / \mathrm{min}^{-1}$ elongation speed during the tests. The finding reveled that neat IPP showed the great extent of cold drawing and the maximum percent elongation, $141 \%$ was achieved with neat IPP. Moreover, it can be deduced from the figure that all IPP based composites showed ductile failure with neck formations. Only, the product with $30 \%$ colemanite failed during the train softening region. Moreover, the maximum ultimate tensile strength was obtained from the product containing the $10 \%$ colemanite content as shown in Figure 3. On the other hand, the figure showed that the percent strain of the products consistently decreased with the increasing of the colemanite content in the IPP matrix. This was the experimental evidence for that the increment in the colemanite content in IPP matrix gave rise to increment in the brittle characteristics of the products. 


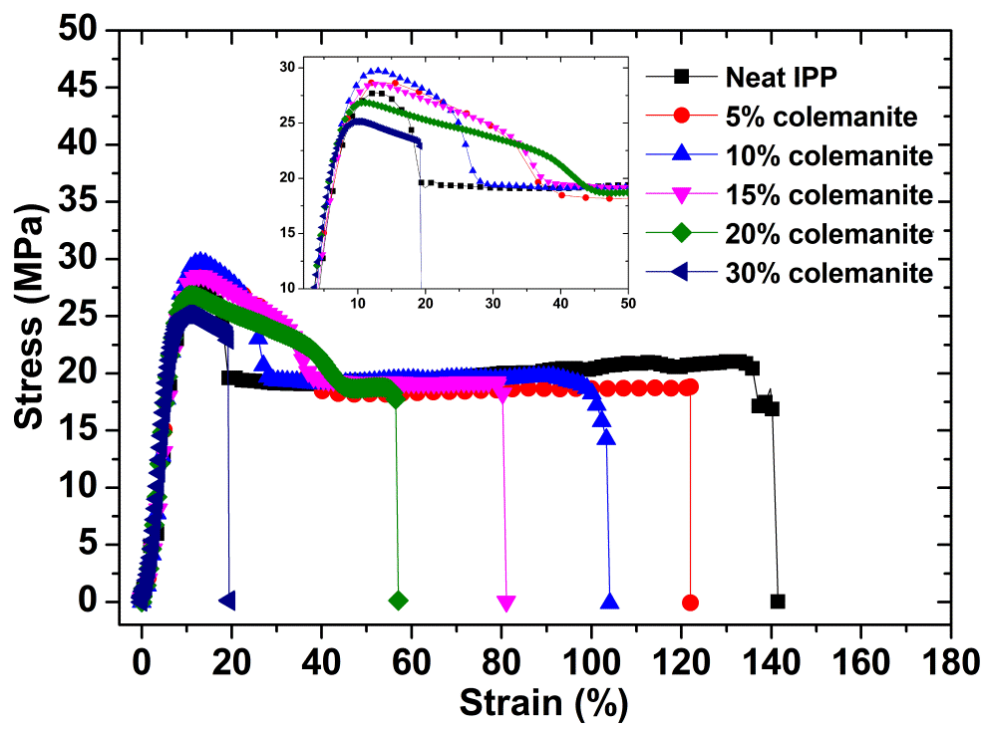

Figure 3. Stress-strain curves of neat IPP and IPP based composites including varying percentage of colemanite.

The significant mechanical properties (ultimate strength, Modulus, impact strength and percent elongation) of the neat IPP and IPP based composites were also studied by discussing the effect of colemanite content in the matrix. The numerically mechanical test findings belonging to the products were tabulated in Table 1 and were drawn in Figure 4. The obtained results depicted that the varying amount of colemanite addition into the IPP matrix affected slightly the all mechanical properties of the products, except for percent elongation. The tensile strength of the products illustrated the increment at the initial addition of the colemanite and reached the maximum strength, $29.74 \mathrm{MPa}$ with the IPP based composite including 10\% colemanite. This value was 3.5\% greater compared to the strength of neat IPP. This increment probably caused by the strengthening effect of the colemanite incorporated into the IPP polymer matrix [41]. After maxima, the consistently decreasing trend was observed in the strength of the products and, at higher content, the tensile strength was found to be $25.14 \mathrm{MPa}$, which was $9.18 \%$ lower than the value that neat IPP had in Figure 4.a. The initiatory increasing trends with colemanite content were also observed in Modulus of the products. The maximum values, $473.63 \mathrm{MPa}$ ( $24.3 \%$ greater than that neat IPP had) were noted at the content of $10 \%$ colemanite for the modulus. After maxima, the dramatic decrements were also recorded in modulus of the products as illustrated in Figure 4.b. However, even at the highest colemanite content (422.92 MPa), Young's Modulus of the products was found to be greater than that neat IPP had. This was evident that the colemanite addition into IPP matrix caused clearly that the products gained the resistance against to deformation. This was believed to result from the enhancement in the alignment and orientation of IPP polymer chain due to the colemanite assisting to IPP chain to orient. On the other hand, the impact strength of the products was also investigated in detail by means of Izod impact tests. It was seen that the change in the colemanite content did not affect considerably the impact strengths of the products. The impact strength findings were presented as the absorbed energy by the products during the test. The results depicted that the impact energy absorption capabilities of the products increased initially with the content, and the maximum value was recorded as $48.94 \mathrm{kj} / \mathrm{m}^{2}$ with the composites containing $10 \%$ colemanite, which was $6.7 \%$ greater compared to neat IPP. After maximum, the decreasing trend was also observed in the impact strength of the IPP based composites, in Figure 4.c.The minimum value, $44.08 \mathrm{kj} / \mathrm{m}^{2}$ related to impact strength was obtained from the product with $\% 30$ colemanite content. The improvement in the impact strength with the initial additions of colemanite presumably caused from that the colemanite particles presenting in the matrix gained to the composites extra energy absorption ability by sharing the stress applied suddenly in the certain regions. However, at further colemanite content, this positive effect may turn into the negative effects. Namely, the presence of larger amount of colemanite microparticles in the IPP matrix probably brought about the formation of 
the agglomeration, which resulted in the appearing the cracks rather than absorbing the energy when the force applied suddenly to the composite materials[42]. Furthermore, Figure 4.d. illustrated that the percent elongation of the composites decreased with the increasing of the colemanite content in the IPP matrix. This may be attributed to that the stiffness of the polymer matrix was smaller than the colemanite inorganic filler. Namely, since the increment in colemanite content gave rise to the increasing of the rigid characteristic of IPP matrices, the free movements of IPP chains in the matrix were probably hindered by colemanite [43].

Table 2. The variation of the mechanical characteristics of neat IPP and the composites containing different content of colemanite.

\begin{tabular}{ccccc}
\hline Species & $\begin{array}{c}\text { Tensile Strength } \\
(\mathbf{M P a})\end{array}$ & $\begin{array}{c}\text { Young's Modulus } \\
\mathbf{( M P a})\end{array}$ & $\begin{array}{c}\text { Impact Strength } \\
\mathbf{( k j / \mathbf { m } ^ { 2 } )}\end{array}$ & $\begin{array}{c}\text { Maximum Strain } \\
(\boldsymbol{\%})\end{array}$ \\
\hline Neat IPP & $27.68 \pm 0.21$ & $381.06 \pm 4.82$ & $45.86 \pm 0.22$ & 141.46 \\
$5 \%$ & $28.65 \pm 0.08$ & $435.10 \pm 3.16$ & $47.12 \pm 0.13$ & 122.03 \\
$10 \%$ & $29.74 \pm 0.11$ & $473.63 \pm 3.97$ & $48.94 \pm 0.19$ & 104.11 \\
$15 \%$ & $28.55 \pm 0.17$ & $455.25 \pm 4.36$ & $46.52 \pm 0.11$ & 81.05 \\
$20 \%$ & $26.85 \pm 0.09$ & $436.00 \pm 3.59$ & $44.75 \pm 0.26$ & 57.08 \\
$30 \%$ & $25.14 \pm 0.15$ & $422.92 \pm 5.51$ & $44.08 \pm 0.16$ & 19.48 \\
\hline
\end{tabular}
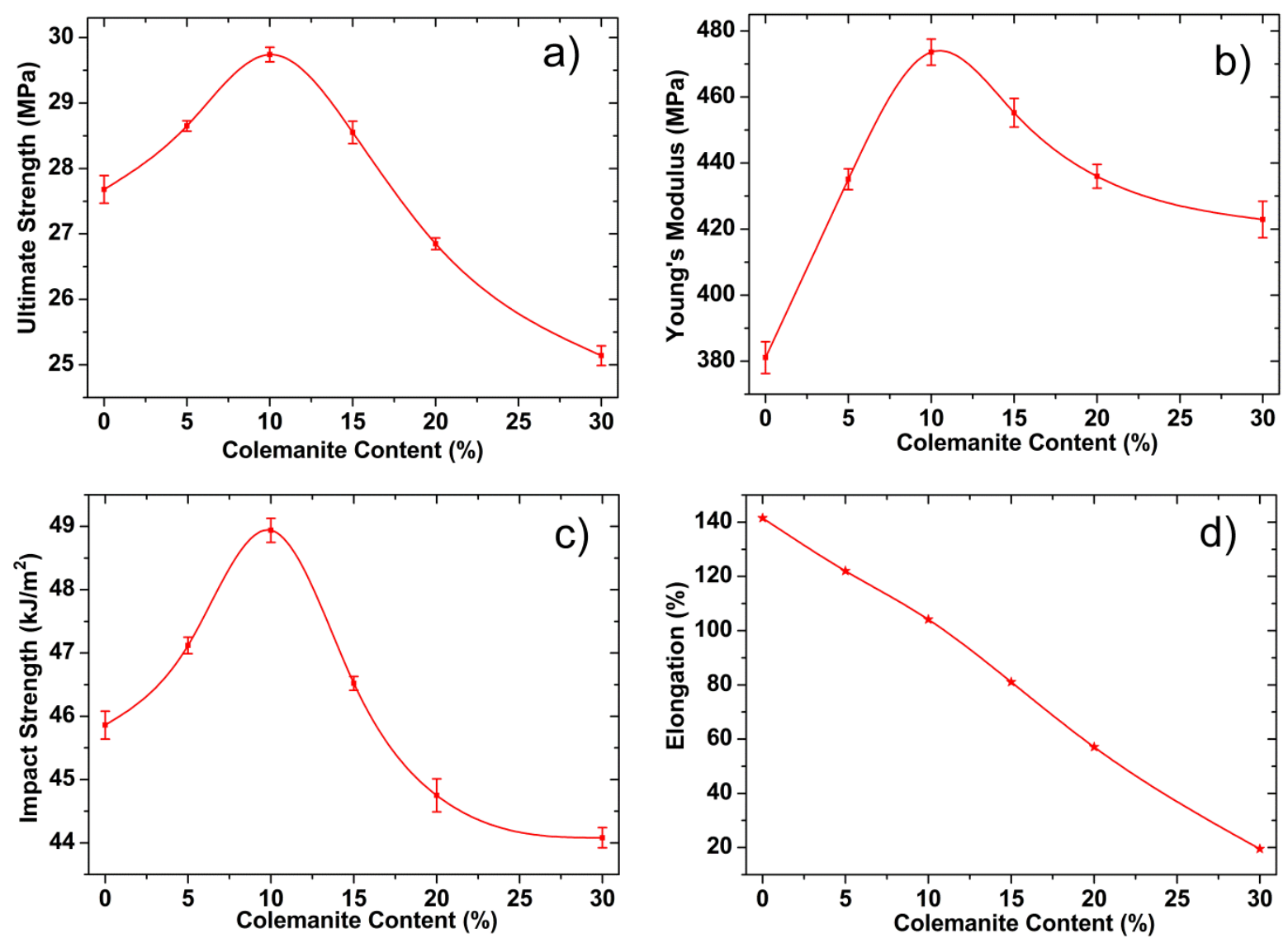

Figure 4. The variation of a) ultimate strength b) Young's modulus) impact strength and d) percent elongation of the neat IPP and the composites with colemanite content. 


\section{CONCLUSIONS}

In this present work, the effect of varying percentage of colemanite addition on the significant microstructural (XRD pattern, unit cell parameter, crystal size) and mechanical (strain vs. stress behavior, tensile strength, Young's Modulus, impact strength, percent elongation) properties of IPP was studied meticulously. The experimental findings revealed that these properties were depended considerably on the percentage of colemanite presenting in IPP matrices. Moreover, it was revealed that the optimum colemanite content was found to be $10 \%$ in order to obtained IPP based composite having advanced characteristics in terms of microstructural and mechanical aspects. Only $\alpha$ form (monoclinic arrangement) in the crystalline domains of IPP was observed from X-ray powder diffraction patterns belonging to neat IPP and IPP based composites without any formation of $\beta$ form (hexagonal arrangements). The increment in the colemanite content in IPP matrices gave rise to both decreasing of the sharpness and broadening of the diffraction peaks [especially $\alpha(110)$ and $\alpha(040)$ ]. This may be seen as the experimental evidence for this disorderly and defects formed in the crystal structure of the IPP. Moreover, it was founded that the colemanite addition into IPP matrix was considerably influential in the microstructural properties of the IPP. Namely, the expansions and contractions in $\boldsymbol{a}$ and $\boldsymbol{b}$ unit cell parameters were recorded depending on the addition of colemanite into IPP matrices, however, $\boldsymbol{c}$ unit cell parameter remained almost unchanged. Furthermore, the obtained results showed that the initial addition of colemanite brought about the reinforcement in tensile strength, Modulus and impact strength of IPP, which probably caused from the strengthening effect of the colemanite incorporated into the IPP polymer matrix. But, at further colemanite content, the mechanical properties get worse. Moreover, it was founded that percent elongation of the products consistently decreased with the increasing of the colemanite content.

\section{ACKNOWLEDGEMENTS}

This work was supported by Bolu Abant Izzet Baysal University, Department of Chemistry. Moreover, the authors send sincere thanks to Eti Mining Operations General Directorate in Turkey for their help to be supplied the colemanite minerals. Furthermore, the authors thank to Seha TİRKES form Middle East Technical University and Firat KARABOĞA from Bolu Abant Izzet Baysal University for permitting use mechanical tests instruments and XRD, respectively.

\section{REFERENCES}

[1] Afzal A, Siddiqi HM, Sarwar S, Rubab Z, Mujahid A. Polymer-particulate composites with differential interfaces: synthesis, characterization, and mathematical modeling to evaluate interface-yield strength correlations. Colloid Polym Sci 2019; 297(4):545-556.

[2] Broitman E. Advances in science and technology of polymers and composite materials. EPolymers 2018;18(1): 1-1.

[3] Oztoprak N, Gunes MD, Tanoglu M, Aktas E, Egilmez OO, Senocak C, Kulac G, Developing polymer composite-based leaf spring systems for automotive industry. Sci Eng Compos Mater 2018; 25(6): 1167-1176.

[4] Tijani SA, Al-Hadeethi Y. The use of isophthalic-bismuth polymer composites as radiation shielding barriers in nuclear medicine. Mater Res Express 2019;6(5).

[5] Martinez-Barrera G, Gencel O, Reis JML. Civil Engineering Applications of Polymer Composites, Int J Polym Sci. 2016. 
[6] Lozano LM, Hong SD, Huang Y, Zandavi H, El Aoud YA, Tsurimaki Y, Zhou JW, Xu Y, Osgood RM, Chen G, Boriskina SV. Optical engineering of polymer materials and composites for simultaneous color and thermal management. Opt Mater Express 2019;9(5):1990-2005.

[7] Morishita T, Matsushita M, Katagiri Y, Fukumori K. A novel morphological model for carbon nanotube/polymer composites having high thermal conductivity and electrical insulation. $\mathrm{J}$ Mater Chem 2011; 21(48):19412-19412.

[8] Ashori A. Nonwood fibers - a potential source of raw material in papermaking. Polym-Plast Technol 2006; 45(10):1133-1136.

[9] Bilogurova L, Shevtsova M, Investigation of the improvement of the physical and mechanical properties of polymer composite materials with nano-sized powders. Materialwiss Werkst 2009;40(4) :331-333.

[10] Fejdys M, Landwijt M, Kucharska-Jastrzabek A, Struszczyk MH. The effect of processing conditions on the performance of UHMWPE-fibre reinforced polymer matrix composites. Fibres Text East Eur 2016; 24(4):112-120.

[11] Chiang CL, Yang JM, Flame retardance and thermal stability of polymer/graphene nanosheet oxide composites. Novel Fire Retardant Polymers and Composite Materials 2017; 73:295-312.

[12] Melo JDD, Dos Santos EA. Mechanical and microstructural evaluation of polymer matrix composites filled with recycled industrial waste. J Reinf Plast Comp 2009; 28(20):2459-2471.

[13] Suzuki N, Zakaria MB, Chiang YD, Wu KCW, Yamauchi Y. Thermally stable polymer composites with improved transparency by using colloidal mesoporous silica nanoparticles as inorganic fillers. Phys Chem Chem Phys 20212;14(20):7427-7432.

[14] Devnani GL, Inha S. Effect of nanofillers on the properties of natural fiber reinforced polymer composites. Mater Today-Proc 2019;18:647-654.

[15] Mehta IK, Kumar S, Chauhan GS, Misra BN. Grafting onto isotactic polypropylene .3. gammarays induced graft-copolymerization of water-soluble vinyl monomers. J Appl Polym Sci 1990;41(5-6):1171-1180.

[16] Rao GSS, Choudhary MS, Naqvi MK, Rao KV. Functionalization of isotactic polypropylene with acrylic acid in the melt: synthesis, characterization and evaluation of thermomechanical properties. Eur Polym J 1996; 32(6);695-700.

[17] Wang B, Yang D, Zhang HR, Huang C, Xiong L, Luo J, Chen XD. Preparation of esterified bacterial cellulose for improved mechanical properties and the microstructure of isotactic polypropylene/bacterial cellulose composites. Polymers-Basel 2016;8(4).

[18] Li QT, Zheng GQ, Dai K, Xie MC, Liu CT, Liu BC, Zhang XL, Wang B, Chen JB, Shen CY, Li Q, Peng XF. Beta-transcrystallinity developed from the novel ringed nuclei in the glass fiber/isotactic polypropylene composite. Mater Lett 2011;65(14):2274-2277.

[19] Huang SL, Liu ZY, Zheng SD, Yang MB. Enhancing the conductivity of isotactic polypropylene/polyethylene/carbon black composites by oscillatory shear. Colloid Polym Sci 2013; 291(12):3005-3011. 
[20] Dutt K, Soni RK, Singh H. Thermal stability and crystallization behavior of TER blends of isotactic polypropylene (iPP)/ethylene-propylenediene rubber (EPDM)/nitrile rubber (NBR). Int J Polym Mater 2012;61(11):864-881.

[21] Mi DS, La RX, Chen WW, Zhang J. Different kinds of transcrystallinity developed from glass fiber/isotactic polypropylene/-nucleation agents composite by microinjection molding. Polym Advan Technol 2016;27(9):1220-1227.

[22] Ghahramani N, Esfahani SAS, Mehranpour M, Nazockdast H. The effect of filler localization on morphology and thermal conductivity of the polyamide/cyclic olefin copolymer blends filled with boron nitride. J Mater Sci 2018;53(23):16146-16159.

[23] Yadav V, Kulshrestha V. Boron nitride: a promising material for proton exchange membranes for energy applications. Nanoscale 2019;11(27):12755-12773.

[24] Shireen F, Nawaz MA, Chen C, Zhang QK, Zheng ZH, Sohail H, Sun JY, Cao HS, Huang Y, Bie, ZL. Boron: functions and approaches to enhance its availability in plants for sustainable agriculture. Int J Mol Sci 2018;19(7) .

[25] Sorensen SS, Johra H, Mauro JC, Bauchy M, Smedskjaer MM. Boron anomaly in the thermal conductivity of lithium borate glasses. Phys Rev Mater 2019;3(7).

[26] Qaid SAS, Alzayed NS, Shahabuddin M, Ramay S, Madhar NA. Comparing the superconducting performance of nC, B4C, and sucrose doped MgB2. Physica C 2020;568.

[27] Guzel G, Sivrikaya O, Deveci $H$. The use of colemanite and ulexite as novel fillers in epoxy composites: Influences on thermal and physico-mechanical properties. Compos Part B-Eng 2016;100:1-9.

[28] Chan-Hom T, Yamsaengsung W, Prapagdee B, Markpin T, Sombatsompop N. Flame retardancy, antifungal efficacies, and physical-mechanical properties for wood/polymer composites containing zinc borate. Fire Mater 2017;41(6):675-687.

[29] Baysal E, Yalinkilic MK, Altinok M, Sonmez A, Peker H, Colak M. Some physical, wood polymer biological, mechanical, and fire properties of composite (WPC) pretreated with boric acid and borax mixture. Constr Build Mater 2017;21(9):1879-1885.

[30] Kuru D, Borazan AA, Guru M. Effect of chicken feather and boron compounds as filler on mechanical and flame retardancy properties of polymer composite materials. Waste Manage Res 2018;36(11):1029-1036.

[31] Kurt R, Mengeloglu F, Meric H. The effects of boron compounds synergists with ammonium polyphosphate on mechanical properties and burning rates of wood-HDPE polymer composites. Eur J Wood Wood Prod 2012;70(1-3):177-182.

[32] Guldas A, Gullu A, Cankaya A. Determination of the rheological properties of polypropylene filled with colemanite. Polym Advan Technol 2017;28(9):1179-1184.

[33] Isitman NA, Kaynak C. Effect of partial substitution of aluminum hydroxide with colemanite in fire retarded low-density polyethylene. J Fire Sci 2013;31(1):73-84. 
[34] Atikler U, Demir H, Tokatli F, Tihminlioglu F, Balkose D, Ulku S. Optimisation of the effect of colemanite as a new synergistic agent in an intumescent system. Polym Degrad Stabil 2006;91(7):1563-1570.

[35] Sahin T. Mechanical and thermal properties of colemanite filled polypropylene. Kgk-Kaut Gummi Kunst 2011;64(9):16-21.

[36] Sen F, Madakbas S, Basturk E, Kahraman MV. Morphology and mechanical properties of thermoplastic polyurethane/colemanite composites, Polym-Korea 2017;41(6):1019-1026.

[37] Soykan U, Cetin S. Reinforcement of high density polyethylene with a side chain LCP by graft copolymerization-thermal, mechanical and morphological properties. J Polym Res 2015;22(11).

[38] Yang BX, Shi JH, Pramoda KP, Goh SH. Enhancement of the mechanical properties of polypropylene using polypropylene-grafted multiwalled carbon nanotubes. Compos Sci Technol 2008; 68(12):2490-2497.

[39] Fereidoon A, Ahangari MG, Saedodin S. Thermal and structural behaviors of polypropylene nanocomposites reinforced with single-walled carbon nanotubes by melt processing method. $\mathbf{J}$ Macromol Sci B 2009;48(1):196-211.

[40] Moly KA, Radusch HJ, Androsch R, Bhagawan SS, Thomas S. Nonisothermal crystallisation, melting behavior and wide angle X-ray scattering investigations on linear low density polyethylene (LLDPE)/ethylene vinyl acetate (EVA) blends: effects of compatibilisation and dynamic crosslinking. Eur Polym J 2005;41(6):1410-1419.

[41] Ersoy OG, Nugay N. Effect of inorganic filler phase on mechanical and morphological properties of binary immiscible polymer blends. Polym Bull 2003, 49(6):465-472.

[42] Hamizah AS, Mariatti M, Othman R, Kawashita M, Hayati ARN. Mechanical and thermal properties of polymethylmethacrylate bone cement composites incorporated with hydroxyapatite and glass-ceramic fillers. J Appl Polym Sci 2012;125:E661-E669.

[43] Pustak A, Denac A, Leskovac M, Svab I, Musil V, Smit I. Morphology and mechanical properties of iPP/silica composites modified with (styrene-b-ethylene-co-butylene-b-styrene) grafted with maleic anhydride. Polym-Plast Technol 2015;54(6):647-660. 